\title{
ASSESSMENT OF VACCINE EFFECTIVENESS DURING MEASLES OUTBREAK IN THE FEDERATION OF BOSNIA AND HERZEGOVINA, 2014-2015
}

\author{
Sanjin Musa ${ }^{1}$, Blaško Topalović ${ }^{2}$, Sutka Ćatić ${ }^{3}$, Zijada Smajlagić ${ }^{4}$ \\ 'Department of Epidemiology, Institute of Public Health of the Federation of Bosnia and Herzegovina, Sarajevo, Bosnia and Herzegovina \\ ${ }^{2}$ Department of Epidemiology, Institute of Public Health of Tuzla Canton, Tuzla, Bosnia and Herzegovina \\ ${ }^{3}$ Department of Hygiene and Epidemiology, Health Care Centre, Bugojno, Bosnia and Herzegovina \\ ${ }^{4}$ Department of Hygiene and Epidemiology, Health Care Centre, Visoko, Bosnia and Herzegovina
}

\section{SUMMARY}

Objective: Between February 2014 and September 2015 a large measles outbreak (5,084 cases) occurred in the Federation of Bosnia and Herzegovina (FB\&H). The aim of this study is to assess the effectiveness of routine measles vaccination in the FB\&H.

Methods: We conducted an analysis of the resurgence period surveillance data and a retrospective cohort study involving primary school aged children in randomly selected schools.

Results: Measles cases occurred among all age groups, mostly among the unvaccinated. Among fully immunized, $2.1 \%$ contracted measles. Measles vaccine effectiveness was high. The study indicates that one dose reduced the risk for measles by $91.9 \%$ (95\% Cl: 81.4-96.4\%), two doses reduced the risk by $97.3 \%(95 \% \mathrm{Cl}$ : 95.5-98.4\%). No evidence of waning immunity was found. Our survey reveals that a significant number of children had no immunization status registered.

Conclusions: The results of this study suggest that the resurgence was likely caused by an accumulation of measles-susceptible children not being vaccinated. This vaccine effectiveness study does not support possible vaccination failure as a contributing factor.

Key words: outbreak, measles, MMR, immunization, vaccine effectiveness

Address for correspondence: S. Musa, Department of Epidemiology, Institute of Public Health of the Federation of Bosnia and Herzegovina, Titova 9, 71000 Sarajevo, Bosnia and Herzegovina. E-mail: s.musa@zzjzfbih.ba

https://doi.org/10.21101/cejph.a4754

\section{INTRODUCTION}

Measles vaccination has been compulsory in Bosnia and Herzegovina since 1970 (1). In 1981, measles-mumps-rubella (MMR) vaccine was included in the schedule for all infants of 12-14 months of age, and the second dose of measles vaccine was scheduled for school children aged 7 years (2). Since 2001, two MMR doses have been scheduled, at 12-18 months and 7 years (or at the first grade of primary school) (3). Due to the current epidemic, the time of the first dose has been moved to the age of 9 months. Introduction of a measles-containing vaccine has resulted in a significant decrease in measles notifications, but during the war that took place in Bosnia and Herzegovina in the early 1990s, even basic childhood vaccinations were affected. In the years after the war echoes of anti-vaccine sentiment have started to spread in the country, fuelled by Wakefield's controversy, which have had further negative impact on the immunization coverage. As a consequence, measles outbreaks have been registered in the last 20 years in the Federation of Bosnia and Herzegovina (FB\&H, the entity of Bosnia and Herzegovina) (Fig. 1) (4). The last measles outbreak occurred from February 2014 to September 2015. In total, 5,084 measles cases were registered.
The first cases were reported in the Central Bosnia Canton among school children and after that they spread across the country (4).

The aim of this study is to assess the effectiveness of routine measles vaccination in the $\mathrm{FB} \& \mathrm{H}$.

\section{MATERIALS AND METHODS}

\section{Case Definition}

Measles diagnosis was confirmed according to the World Health Organization (WHO) guidelines (5). The clinical criteria for measles were fever, maculopapular rash (i.e. non-vesicular rash), and cough or coryza (i.e. runny nose), or conjunctivitis (i.e. red eyes). The laboratory criteria for measles surveillance case confirmation were measles IgM antibody detection, or measles virus isolation, or measles viral RNA detection by RT-PCR, or a significant rise in measles $\operatorname{IgG}$ antibody in paired sera.

All suspected cases were investigated and classified based on clinical, laboratory and epidemiological data, based on the WHO case definition (5). 


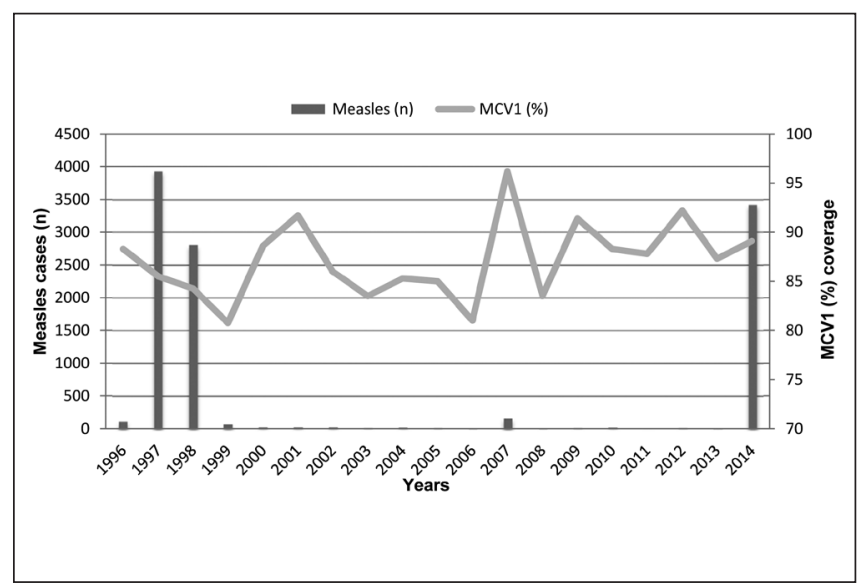

Fig. 1. Annually reported measles cases and MCV1 coverage, Federation of Bosnia and Herzegovina, 1996-2014.

MCV1 - measles-containing-vaccine 1st dose

Laboratory findings of initial cases revealed the presence of D8 measles virus genotype (6).

\section{Measles Surveillance Results}

We conducted an analysis of the resurgence period surveillance data, from 1 February 2014 (the first month with confirmed measles cases) to 30 September 2015. Measles cases reported through surveillance system and weekly reports from 10 districtlevel public health departments were analysed by age and vaccination status.

\section{Retrospective Cohort Study}

We also conducted a retrospective cohort study involving primary school aged children in randomly selected schools in four cantons where measles cases were registered (Tuzla Canton, Central Bosnia Canton, Zenica-Doboj Canton, and HerzegovinaNeretva Canton). Twenty primary schools that had registered measles cases were included. The study included all students in 40 classes with one or more registered measles cases in the period from February 2014 to September 2015. A list with the names of students infected with measles was obtained from the services of epidemiology at the municipality level.
Demographic information was collected: school, grade, classroom, age, and sex. Immunization status, the number of MMR doses, and the date of the last MMR dose were obtained from personal medical records.

Vaccine effectiveness was calculated using the formula (7):

$$
\mathrm{VE}=\frac{\mathrm{ARU}-\mathrm{ARV}}{\mathrm{ARU}} \times 100
$$

where $\mathrm{VE}=$ vaccine efficacy, $\mathrm{ARU}=$ attack rate in the unvaccinated population, and $\mathrm{ARV}=$ attack rate in the vaccinated population.

Attack rate and vaccine efficacy with 95\% CI were evaluated. Analyses were performed using Stata statistic software, version 8.0.

\section{RESULTS}

\section{Surveillance}

Measles cases occurred among all age groups, mostly among the unvaccinated and people with unknown vaccination status. Among the fully immunized people, 2.1\% suffered measles. Of 5,084 confirmed measles cases, 525 (10.3\%) were among children aged $<1$ year, too young to be vaccinated; and 843 (16.6\%) were among children aged 1-4 years, among them $658(78.1 \%)$ were unvaccinated children; and 87 (10.6\%) were children who had received one dose of MMR vaccine. There are a significant number of persons with unknown immunization status (Table 1).

\section{Retrospective Cohort Study}

Participants were selected from 40 classes with 66 (7.3\%) measles cases among 906 study children. The study children had a median age of 10 years (range $6-15$ years); among them 424 $(46.8 \%)$ were females.

Immunization status was unknown for 95 (10.5\%) students and therefore these cases were excluded.

The measles attack rate was $36.8 \%$ among children who received 0 doses, $3.0 \%$ among children who received 1 dose, and $0.99 \%$ among children who received 2 doses (Table 2).

Table 1. Vaccination status and age of measles cases, Federation of Bosnia and Herzegovina, 2014-2015 (N=5,084)

\begin{tabular}{|l|c|c|c|c|c|c|c|c|c|c|}
\hline \multirow{2}{*}{ Age } & \multicolumn{2}{|c|}{ Unvaccinated } & \multicolumn{2}{|c|}{ One dose } & \multicolumn{2}{c|}{ 2 doses } & \multicolumn{3}{c|}{ Unknown } & \multicolumn{2}{c|}{ Total } \\
\cline { 2 - 12 } & $\mathbf{n}$ & $\%$ & $\mathbf{n}$ & $\%$ & $\mathbf{n}$ & $\%$ & $\mathbf{n}$ & $\%$ & $\mathbf{n}$ & $\%$ \\
\hline$<1$ & 471 & 89.7 & 0 & 0 & 0 & 0 & 54 & 10.3 & 525 & 10.3 \\
\hline $1-4$ & 658 & 78.1 & 87 & 10.6 & 0 & 0 & 96 & 11.4 & 843 & 16.6 \\
\hline $5-9$ & 543 & 72.4 & 83 & 11.1 & 25 & 3.3 & 99 & 13.2 & 750 & 14.8 \\
\hline $10-14$ & 445 & 66.8 & 63 & 9.5 & 21 & 3.2 & 137 & 20.6 & 666 & 13.1 \\
\hline $15-19$ & 551 & 61.3 & 90 & 10.0 & 34 & 3.8 & 224 & 24.9 & 899 & 17.7 \\
\hline $20-29$ & 330 & 51.5 & 56 & 8.7 & 17 & 2.7 & 238 & 37.1 & 641 & 12.6 \\
\hline $30+$ & 315 & 41.4 & 42 & 5.5 & 10 & 1.3 & 393 & 51.7 & 760 & 14.9 \\
\hline Total & 3,313 & 65.2 & 423 & 8.3 & 107 & 2.1 & 1,241 & 24.4 & 5,084 & 100.0 \\
\hline
\end{tabular}


Table 2. Measles attack rates and vaccine effectiveness (VE) by the number of vaccine doses, primary school cohort, Federation of Bosnia and Herzegovina, 2014-2015

\begin{tabular}{|l|c|c|c|c|c|}
\hline Doses $(\mathbf{n})$ & Cases $(\mathbf{n})$ & Total & Attack rate & VE & ${\text { 95\% } \mathrm{Cl}^{*}}$ \\
\hline 0 & 35 & 95 & 36.8 & $+^{* *}$ & \\
\hline 1 & 3 & 100 & 3.0 & 91.9 & $81.4-96.4$ \\
\hline 2 & 6 & 606 & 0.99 & 97.3 & $95.5-98.4$ \\
\hline
\end{tabular}

${ }^{*}$ Confidence interval

${ }^{* *}$ Reference category

Table 3. Measles attack rates and single dose vaccine effectiveness (VE) by the years since vaccination, primary school cohort, Federation of Bosnia and Herzegovina, 2014-2015

\begin{tabular}{|l|c|c|c|c|c|}
\hline Years since vaccination & Cases $(\mathrm{n})$ & Total & Attack rate & VE & $95 \% \mathrm{Cl}^{*}$ \\
\hline Not vaccinated & 35 & 95 & 36.8 & $+^{* *}$ & \\
\hline$\leq 5$ & 1 & 20 & 5.0 & 86.4 & $44.5-96.7$ \\
\hline $6-14$ & 2 & 76 & 2.6 & 92.9 & $81.3-97.3$ \\
\hline
\end{tabular}

${ }^{*}$ Confidence interval

${ }^{* *}$ Reference category

Single-dose vaccine effectiveness was $91.9 \%(81.4-96.4 \%)$, and two-dose vaccine effectiveness was 97.3\% (95.5-98.4\%), which is significantly higher (Table 2).

Single-dose vaccine effectiveness was statistically similar between students vaccinated 5 years and more in the past (Table 3 ).

\section{DISCUSSION}

In the WHO European Region, vaccine coverage of $\geq 95 \%$ with two doses of a measles-containing vaccine through high-quality routine immunization services must be achieved and maintained in order to terminate endemic transmission of measles virus (5).

Despite the efforts to eliminate measles and rubella in Europe by 2015 , the number of measles cases has been increasing in numerous European countries in the last few years (8-11). Vaccine hesitancy has become a growing focus of attention for public health researchers (12).

Between 1 January 2014 and 1 March 2015, the WHO received notifications of over 23,000 cases of measles in the WHO European Region. Significant numbers of measles cases have been reported in Kyrgyzstan, Bosnia and Herzegovina, Croatia, Georgia, Germany, Italy, Kazakhstan, Russia, and Serbia. Measles virus D8 has been the most commonly identified circulating genotype (13).

In the United States, during the period from 4 January to 2 April 2015, a total of 159 measles cases (in 155 US residents and four foreign visitors) from 18 states and the District of Columbia were reported to the Centers for Disease Control and Prevention (CDC) (14).

The FB\&H experienced a large measles epidemic in the period between February 2014 and September 2015, with 5,084 registered cases. A large outbreak of measles provided an opportunity to assess vaccine effectiveness. The resurgence was generally characterized by outbreaks with cases occurring among all age groups as a result of the long-standing gaps in vaccination (Table 1).

According to the CDC Pink Book, measles antibodies develop in approximately $95 \%$ of children vaccinated at 12 months of age and in $98 \%$ of children vaccinated at 15 months of age. Most people who fail to respond to the first dose will respond to the second dose (15).

Our study confirmed the single-dose vaccine effectiveness of $91.9 \%(81.4-96.4 \%)$, and two-dose vaccine effectiveness of $97.3 \%$ (95.5-98.4\%), showing no evidence of waning immunity (Table 2).

A similar study in Romania reported that one dose reduces the risk of measles by $89 \%$ ( $85-91 \%$ ), two doses reduce the risk by $96 \%$ (92-98\%). Waning immunity was not identified as a risk factor since vaccine effectiveness was similar for children vaccinated years ago (16).

The results of an Australian study (vaccine effectiveness at the population level) also demonstrated that the vaccine had been effective, at least one-dose effectiveness was 98.7\% (97.9-99.2\%), and two-dose effectiveness was $99.7 \%$ (99.2-99.9\%) (17). Finally, in the outbreak study from the Republic of the Marshall Islands, one-dose vaccine effectiveness was 92\% (67-98\%), and two-dose vaccine effectiveness was $95 \%$ (82-98\%) (18).

MMR vaccine failure may occur because of passive antibody in the vaccine recipient, damaged vaccine, incorrect records, or other possible reasons (15).

Studies suggest that MMR vaccination administered after 15 months of age provides a substantial increase in the vaccine effectiveness $(19,20)$. Due to a limited number of participants in this study, this analysis has not been performed.

Some studies indicate that the vaccination coverage should be at least 0.971 (95\% CI: $0.961-0.978)$ to prevent major outbreaks unless the vaccination coverage (21). They argue that the effectiveness of a vaccine in a population cannot be judged solely by its estimated efficacy, but also depends on the pathogen transmissibility $(18,21)$

\section{CONCLUSIONS}

The results of this study suggest that the resurgence was likely caused by an accumulation of measles-susceptible children not vaccinated due to lower immunization coverage. This vaccine effectiveness study does not support possible vaccination failure as 
a contributing factor. Our survey reveals that a significant number of children had no immunization status registered.

\section{Acknowledgements}

The authors thank the epidemiologists and technicians from the Hygiene and Epidemiology Departments at the municipal level (Gračanica, Lukavac, Živinice, Tuzla, Banovići, Bugojno, and Visoko) for their support in student's immunization data collection.

\section{Conflict of Interest}

None declared

\section{REFERENCES}

1. Order on the program of compulsory immunization of the population against infectious diseases in 1970, No. 266. Službeni list SRBiH. 1969;25(33):446-8.

2. Order on the program of compulsory immunization of the population against infectious diseases in 1981, No. 324. Službeni list SRBiH. 1980;36(34):1327-30

3. Order on the program of compulsory immunization of the population against infectious diseases in 2001, No. 205. Službene novine FBiH. 2001;8(21):442-6.

4. Institute for Public Health FB\&H. Epidemiological surveillance on communicable diseases in the Federation of Bosnia and Herzegovina, 2014. Sarajevo - Mostar: Institute for Public Health FB\&H; 2015.

5. World Health Organization. Surveillance guidelines for measles, rubella and congenital rubella syndrome in the WHO European Region, update December 2012. Copenhagen: WHO Regional Office for Europe; 2012.

6. Hukic M, Ravlija J, Karakas S, Mulaomerovic M, Dedeic Ljubovic A, Salimović-Besic I, et al. An ongoing measles outbreak in the Federation of Bosnia and Herzegovina, 2014 to 2015. Euro Surveill. 2015 Mar 5;20(9). pii: 21047.

7. Orenstein WA, Bernier RH, Hinman AR. Assessing vaccine efficacy in the field. Further observations. Epidemiol Rev. 1988;10:212-41.

8. Mankertz A, Mulders MN, Shulga S, Kremer JR, Brown KE, Santibanez $\mathrm{S}$, et al. Molecular genotyping and epidemiology of measles virus transmission in the World Health Organization European Region, 2007-2009. J Infect Dis. 2011 Jul;204 Suppl 1:S335-42.

9. Santibanez S, Prosenc K, Lohr D, Pfaff G, Jordan Markocic O, Mankertz A. Measles virus spread initiated at international mass gatherings in Europe, 2011. Euro Surveill. 2014 Sep 4;19(35). pii: 20891.

10. Filia A, Riccardo F, Del Manso M, D'Agaro P, Magurano F, Bella A. Measles outbreak linked to an international dog show in Slovenia - primary cases and chains of transmission identified in Italy, November to December 2014. Euro Surveill. 2015 Mar 5;20(9). pii: 21050.
11. Pegorie M, Shankar K, Welfare WS, Wilson RW, Khiroya C, Munslow $\mathrm{G}$, et al. Measles outbreak in Greater Manchester, England, October 2012 to September 2013: epidemiology and control. Euro Surveill. 2014 Dec 11;19(49). pii: 20982.

12. MacDonald NE, SAGE Working Group on Vaccine Hesitancy. Vaccine hesitancy: definition, scope and determinants. Vaccine. 2015 Aug $14 ; 33(34): 4161-4$.

13. World Health Organization. Global Alert and Response (GAR). Measles WHO European Region [Internet]. Geneva: WHO; 2015 [cited 2015 Sep 10]. Available from: http://www.who.int/csr/don/6-march-2015-measles/ en/.

14. Clemmons NS, Gastanaduy PA, Fiebelkorn AP, Redd SB, Wallace GS Centers for Disease Control and Prevention (CDC). Measles - United States, January 4-April 2, 2015. MMWR Morb Mortal Wkly Rep. 2015 Apr 17;64(14):373-6.

15. Hamborsky J, Kroger A, Wolfe S, editors; Centers for Disease Control and Prevention. Epidemiology and prevention of vaccine-preventable diseases. 13th ed. Washington D.C.: Public Health Foundation; 2015.

16. Hennessey KA, Ion-Nedelcu N, Craciun MD, Toma F, Wattigney W, Strebel PM. Measles epidemic in Romania, 1996-1998: assessment of vaccine effectiveness by case-control and cohort studies. Am J Epidemiol. 1999 Dec 1;150(11):1250-7.

17. Pilsbury A, Quinn H. An assessment of measles vaccine effectiveness, Australia, 2006-2012. Western Pac Surveill Response J. 2015 Jul 9;6(3):43-50.

18. Marin M, Nguyen HQ, Langidrik JR, Edwards R, Briand K, Papania $\mathrm{MJ}$, et al. Measles transmission and vaccine effectiveness during a large outbreak on a densely populated island: implications for vaccination policy. Clin Infect Dis. 2006 Feb 1;42(3):315-9.

19. Defay F, De Serres G, Skowronski DM, Boulianne N, Ouakki M, Landry $\mathrm{M}$, et al. Measles in children vaccinated with 2 doses of MMR. Pediatrics. 2013 Nov; 132(5):e1126-33.

20. De Serres G, Boulianne N, Defay F, Brousseau N, Benoit M, Lacoursiere $\mathrm{S}$, et al. Higher risk of measles when the first dose of a 2-dose schedule of measles vaccine is given at 12-14 months versus 15 months of age. Clin Infect Dis. 2012 Aug;55(3):394-402.

21. Van Boven M, Kretzschmar M, Wallinga J, O'Neill PD, Wichmann O, Hahné S. Estimation of measles vaccine efficacy and critical vaccination coverage in a highly vaccinated population. J R Soc Interface. 2010 Nov $6 ; 7(52): 1537-44$. 